\title{
Gap Analysis and Optimization of Process Parameters in a Manufacturing Firm
}

\author{
Usman Ghani $^{1}$, Mubashir Hayat ${ }^{2}$, Iftikhar Hussain ${ }^{3}$ \\ ${ }^{1,2}$ Department of Mechanical Engineering, \\ University of Engineering and Technology Peshawar, Jalozai Campus \\ ${ }^{3}$ Department of Industrial Engineering UET Peshawar \\ 1'usmanghani@uetpeshawar.edu.pk
}

\begin{abstract}
Nowadays companies want quality products to satisfy customer expectations along with high profit rates. The proposed research considers a manufacturing firm which produces mates. The mates in the firm are categorized by color, material used and size of the pipes used in the mates. The production line struggles to meet the defects free production particularly to overcome the size variations, color uniformity and weight of the raw material consumed. The proposed research is focused to analyze the three main process parameters such as working temperature, pressure and cooling temperature. These process parameters are then optimized using design of experiments and best possible combination is recommended for future production. For each factor the experiment is replicated two times and is analyzed for two different material flow.
\end{abstract}

Keyword: Manufacturing Firm, Gap Analysis, Optimization, Factorial Design, Mat Pipes.

\section{INTRODUCTION}

Gap analysis is a combination of different techniques and processes to measure the current performance of an organization relatively to organization's internals benchmarks. Gap can also be considered as the difference between present and future state of an organization intent to achieve. Technically GAP analysis can be used to assess an enterprise that can meet its needs using its present capabilities. The capabilities may be examined for improvement including staff competencies, facilities, applications, technical infrastructure, processes, lines of business, etc. A gap analysis starts with current state followed by defining future state which include all the processes and characteristics of an organization that needs an improvement. The more the focus is on broader level, the more it will achieve the whole business area while targeting the entire business. Alternatively, If the focus is on shorter level, it can be either quantitative i.e. customer demand or can be qualitative i.e. examining the workplace. The factors that may contributes to gaps can be described either qualitatively or quantitatively.

MKB is a group of companies located in Industrial Estates Peshawar, Pakistan where they are producing mats. The production process of MKB is shown in figure 1. Raw material is initially stored in warehouse and taken to extrusion section when required. Before the material is fed to the extrusion machine, it is preheated up to certain temperature. The pipes used in the mates are extruded and then checked in the quality department. The good quality pipes are send to the weaving section while the poor quality pipes are disposed as waste. The exhaust gases from the weaving section are used in the heater for preheating of the raw material. After weaving the mates are stored initially and then send to the customers when orders are placed.

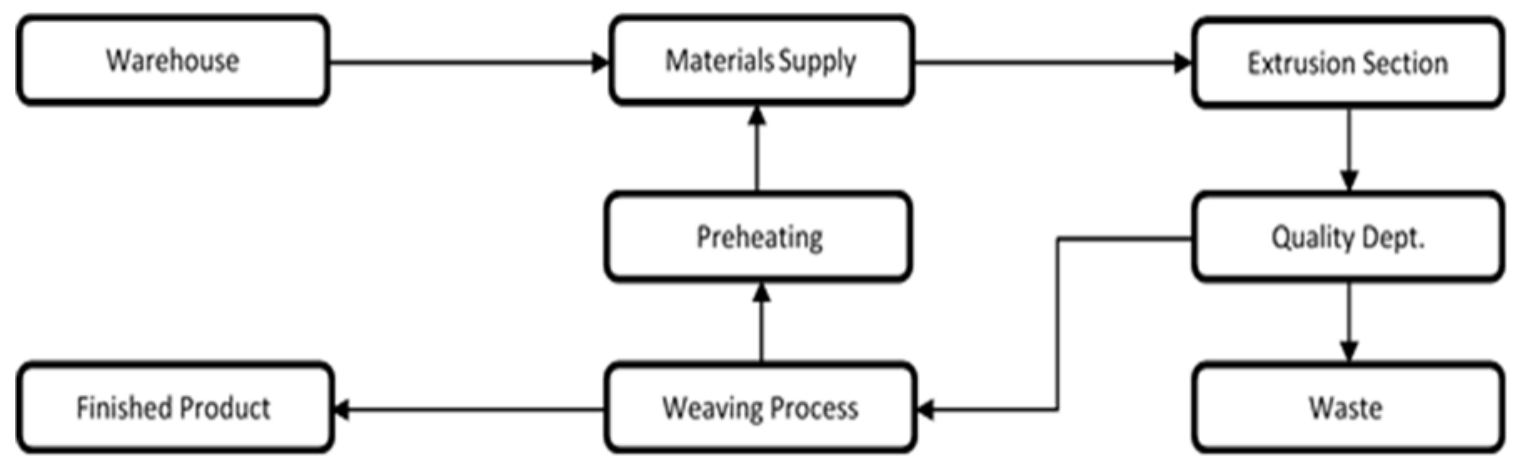

Fig. 1. Production process of MKB

MKB is using 96 extruder machines distributed in five section called extrusion section. Each section is differentiated from each other on the basis of producing different colors. These colors are red, white, yellow, green and light brown. These are further shifted for weaving process. These are also distributed into weaving section. Two section are made for weaving section. In extrusion section, 1 extruder machine utilizes 5 bag of pure poly propylene per day where $1 \mathrm{bag}$ contain $25 \mathrm{~kg}$. They produces pipes up to range of 180-190/min and use $12 \mathrm{hr} / \mathrm{shift}$ and $2 \mathrm{shift} /$ day. Two sections of extruder machine using pure poly propylene to produce mats of high quality and 
standard where other three sections are using for recycled material. These pure poly propylene and recycled material are explained later in this chapter. In any organization there are range of problems most of the problems are associated with the machines producing the waste. These machines are the main cause for the more waste in the organization, there are number of techniques used in the organization to reduce the waste so GAP Analysis helps to achieve the company mission statement by first identifying those problem causing factor then give an appropriate estimation of factors that may influence the system in a positive way.

First of all an organization need to define proper objectives in accurate way that can help in achieving the desire state. If the objectives are not clear, the outcomes may deviate from desired path. Secondly, an organization needs to identify the main reason of poor performance of sections that may affect profit and growth in long run. This can be done through brain storming, employees interviews and documents review sessions etc. Finally, in order to overcome the related issues, some actions are planned. Once the present and future expectations are known then the only step remaining is the implementation of action plans to resolve the identified issues/gaps. This may involve a number of steps like hiring skilled employees, procuring extra machines and equipment, offering perks and incentives to get the best out of employees.

\section{A. Problem Statement}

Industrial waste is a common issue in most of the organizations. The production process of MKB as depicted in figure 1 is also facing the same issue in one of its most important section i.e. extrusion. Extrusion is most critical because the liquid solvent are converted into solid shapes pipes in this section. Pipes which doesn't comply the standards are rejected in this section. These wastes results in the gaps between the actual and desired results. Here the problem is to identify the factors like temperature, pressure etc in the extrusion section and to obtain their best possible combination for the desired results.

\section{B. Objectives of the Research}

The purpose of the research is to perform the gap analysis and to achieve the optimum or desired state for any recognized area that needs improvement. Different gaps are identified in order to be filled or bridged. It includes waste minimization, quality improvement, identifying significant factors, performance measurements and factors affecting the process. Shortly, following are the main objectives of the research.

- To find out the factors effecting production.

- To analyze the gaps between present and future state.

- To achieve desired state and improve production.

\section{LITERATURE REVIEW}

Several concepts and approaches needs to be discussed for measuring and finding the gaps in one of the manufacturing section of matt producing section. Here design of experiments is used as a gap analysis tool. A factorial approach has been adopted where we found the individual and the combined effect of the different factors that effect a process and system, in this case two factor at a time has been used for measuring the effect of two factor at a time on a process. The manufacturing strategy is one of the most important component of the business strategy. W. Skinner suggested that the manufacturing has a potential to decide the company strength or weakness [1]. S.C. Wheelwright stated that manufacturing can help support the firm and can make it a competitive company [2]. He defined the four basic competitive advantages of any organization in the field of the manufacturing, these four advantages were; quality, cost efficient, effectiveness and dependability. This framework was very successful and greatly influence the way manufacturing organization was working. Hayes and Wheelwright worked out to find more competitive advantages that a business have to help them be more competitive, since then many researcher explore the role of manufacturing strategy implementation and its role of the business unit [3]. Many studies have shown that well-formulated and great performing manufacturing strategies, aligned with goals and strategies can produce better results. C. Tunaly presented a case study where he formulated manufacturing strategy outperforms the one that doesn't [4]. M. A Nobel showed that high productive firms have clearly defined competitive strategies [5].

The industry week census of manufacturers reported the practices that most of the American manufacturer is in favor of and these practices most likely to produce the best performers in the manufacturing sector. G. Teninecz and $\mathrm{H}$. Wang stated that using cold forging and extrusion is more efficient than any other manufacturing processes use in any industry, it has the advantages such as, minimum material waste, high-dimensional accuracy, complete elimination of the machining, good surface fitness, better mechanical properties of the products then those of the original product due to favorable grain flow $[6,7]$. Most of the cold-forge process is done through trial and error and on the basis of experience which costs too much because of the rejection of the parts [8]. More studies on the relationship between the manufacturing practices has been performed that lies in the domain region of advanced manufacturing technology, quality, pp\&c (production planning and control), just-in-time and lean production. Extrusion is one of the processes that we use for producing parts of different size and shape. To figure out the relationship between manufacturing strategies, performances and practices there need efforts. Manufacturing 
practices are the one that required performing higher. Further researchers who have worked in this research related area are Lehmann et al [9], Dong, Jia et al [10], Larson, David [11], Y.Kim, J.Lee [12].

Some efforts are made to figure out how manufacturing practices, performances and strategies can be related to each other. For this we categorize our efforts into two categories: analytical and predicative. The first one interests in finding out under what conditions manufacturing practices can be more effective in objective of attaining higher performance. R.H Chenhall has shown that how the use of the management techniques can enhance the performance of an organization under particular strategic orientation, such as low-price strategy and emphasizing product differentiation [13]. based on 1991 survey of over 60 manufacturing organization in Belgium, a study has compared top-priorities of competitive strategy, performance measurement and improvement programs. It reveals that there is a still inconsistency between business strategy, improvement actions and performance measurement systems. Brundtland defines sustainability as "meeting the needs of the present generation without compromising the ability of future generation to meet their own needs" [14]. There are number of companies that increase their saving, some example are: Brandix reduce water usage by $58 \%$, energy usage by $46 \%$ resulting in $30-40 \%$ of the reduction in the cost of operations. Ford Motor reduce their energy usage by $30 \%$ and water usage by $43 \%$. Analysis of these companies show that each of them, in one way or other fit into the three categories, material, energy and waste (mew) process flow category [15]. When you are drawing less waste and use less power to give the desired output then this lead to the financial and economic benefits, which impact the company growth and the customer trust.

One thing to keep in mind that design of experiment is one of the powerful tool for engineers and scientists to use it as a tool for performance improvement. There are many more techniques which we can use to improve performance such as quality function deployment, statistical process control (spc) and process capability studies etc. However we will use design of experiments (doe) as a tool here. Statistical analysis of a model is one of the tools we will use to carry out gap analysis in the manufacturing firm. The statistical approach to the design of experiments and the analysis of the variance technique was proposed [16]. These techniques help us in finding the most significant figure. If you are talking about in manufacturing then design of experiments help us in finding the factor that is significant in manufacturing and factor that is not. The classical model of design of experiment was developed $[17,18]$. The Taguchi suggested the design process consist of three phases namely system design, tolerance design and parameter design.

Both of these approaches provide a very strong evidence of finding the process control and the key factors that affecting the performance of the system. The DOE technique permit us to select many variables can be identified [19]. The grouping of these variables into families and then finding out the most effective or significant variable based on the statistical significance providing a great chance of identifying the most influential factor [20]. Shainan identifies as each factor and divide them into three basic categories; red $\mathrm{x}$, pink $\mathrm{x}$, and pale pink $\mathrm{x}$. Red $\mathrm{x}$ is the major variance causing factor, pink $\mathrm{x}$ is the second and pale pink $\mathrm{x}$ is the third major variance dominating factor. Both of the design generated appear to be similar, some industries use taguchi method while other used traditional method of solving problems. The taguchi and the traditional method, both of the method we have discussed, used for the optimization of the machining operations in the industry. Grinding, unlike other machining operation is costly, and should be utilized under feasible conditions to achieve high quality and productivity. In this paper we used the two-factor at a time experiment to find the most influential factor.

\section{DATA COLLECTION}

Data collection can be done through different techniques for different kind of data. These techniques are Questionnaire model, communication through email, WhatsApp, documentation \& records, expertise opinion, research models and examining the overall process. In this case, the data collection is done through documentation, expertise ideas and some observation or by examining the overall production process for some period of time. The most of the data collection is done through examining the process up to some specific time to make sure that the data is correct and accurate for analyses. While collecting data, there are three main factors which can affect the overall process of production in extrusion section. These factors are

- Temperature

- Pressure

- Cooling temperature

These factors are further consider for analysis because these are quantitative and vary from time to time within process.

\section{A. Temperature}

Temperature can be crucial and a factor effecting aspect. The industry only rely on weight of the pipe in spite of quality control aspect. To check the quality of the pipe produced, the quality department check the weight of the pipes as it is up to standard or not. The industry uses a ranges of temperatures for melting of pure poly propylene and reused materials which is pre-heated first. These temperature ranges vary from $220^{\circ} \mathrm{C}$ to $235^{\circ} \mathrm{C}$. whenever the temperature of the melting materials gets high; let's say $230-235^{\circ} \mathrm{C}$, the weight of the pipe gets low value and 
when the temperature drops down i.e. $220-225^{\circ} \mathrm{C}$, the weight of the pipe gets high value. In simple words, the temperature of the raw material is inversely proportion to the weight of the pipes. The up and down in temperature of raw material results an effect on the weight of the pipe. The data has been collected for temperature by conducting a keen observation for more than 1 hour and generated two replicates for two different types of pipe sizes. The data is shown in the table I.

Table I. Effect of temperature on weight of the pipe

\begin{tabular}{|c|c|c|}
\hline \multicolumn{3}{|c|}{ Temperature } \\
\hline \multirow{2}{*}{ 3-feet } & $\mathbf{2 2 0}^{\circ} \mathbf{C}[$ Low (-)] & $\mathbf{2 3 5}^{\circ} \mathbf{C}[$ High (+)] \\
\cline { 2 - 3 } & 4.20 & 3.51 \\
\hline \multirow{2}{*}{ 4-feet } & 4.31 & 3.62 \\
\cline { 2 - 3 } & 6.82 & 5.51 \\
\cline { 2 - 3 } & 6.90 & 5.65 \\
\hline
\end{tabular}

The values shown in the table are the response variables i.e. low and high values which are expressed in weight. Two replicates were taken for each type of pipe sizes for further analysis. Although $2 \mathrm{k}$ factorial design has been used for analysis which needs to take more replicates for precise result. Therefore two replicates has been taken.

\section{B. Pressure}

Pressure is one of the most crucial factor in all of these. Its effect is quite colossal when it is not handle with proper care and attention. Pressure used, in this process, to make the diameter for pipe which is almost same for three types of pipe size. Different pressure ranges are used for the production process and these ranges vary $0.40 \mathrm{MPa}$ $0.42 \mathrm{MPa}$. The data is shown in the table II.

Table II. Effect of pressure on weight of the pipe

\begin{tabular}{|c|c|c|}
\hline \multicolumn{3}{|c|}{ Pressure } \\
\hline \multirow{2}{*}{ 3-feet } & 0.40MPa[ Low (-)] & 0.42MPa [High (+)] \\
\cline { 2 - 3 } & 3.60 & 4.10 \\
\hline \multirow{2}{*}{ 4-feet } & 3.73 & 4.00 \\
\cline { 2 - 3 } & 5.61 & 6.10 \\
\cline { 2 - 3 } & 5.56 & 6.21 \\
\hline
\end{tabular}

Pressure and the effect of pressure on weight of the pipe relation is somehow directly proportional to each other. When the pressure value increases, the weight of the pipe increases and when pressure value decreases, the weight of the pipe also decreases. Waste is generated in both cases. The data collected for pressure effect is shown in the table below. The values shown in the table are the response variables i.e. low and high values which are expressed in weight. Two replicates were taken for each type of pipe size.

\section{Cooling Temperature}

Cooling temperature can also effect the overall production. The mats pipe, before entering into cutting section in extrusion machine, entered into cooling station/chamber. The cool water is present to cool down hot pipe coming out of die. The water has to be replaced when use for some period of time because it changes its temperature (lower) and such temperatures cannot cool down the hot pipes as up to standards and will generate waste none the less. The data is shown in the table III.

Table III. The effect of cooling temperature on weight of the pipe

\begin{tabular}{|c|c|c|}
\hline \multicolumn{3}{|c|}{ Cooling temperature } \\
\hline & $\mathbf{5}^{\circ} \mathbf{C}[$ Low (-)] & $\mathbf{9}^{\circ} \mathbf{C}[$ High (+)] \\
\hline \multirow{2}{*}{ 3-feet } & 4.34 & 3.43 \\
\cline { 2 - 3 } & 4.41 & 3.52 \\
\hline \multirow{2}{*}{ 4-feet } & 6.60 & 5.55 \\
\cline { 2 - 3 } & 6.73 & 5.40 \\
\hline
\end{tabular}

These temperature ranges vary from $5^{\circ} \mathrm{C}$ to $9^{\circ} \mathrm{C}$. whenever the temperature of cooling water gets high; let's say 7$9^{\circ} \mathrm{C}$, the weight of the pipe gets low value and when the temperature drops down i.e. $5-6^{\circ} \mathrm{C}$, the weight of the pipe gets high value. In other words, the cooling temperature is inversely proportional to the weight of the pipes. The up and down in cooling temperature results an effect on the weight of the pipe which is actually response variable. 


\section{DATA ANALYSIS}

For data analysis, $2 \mathrm{k}$ factorial design has been used. As there are three factors which has been selected for further processing after eliminating some factors which are not needed for analysis. The selected factors has two different levels, low and high, resulting in different response variable. In Mats production process, the response variable is weight of the pipe produced. It is the reason behind that we selected $2 \mathrm{k}$ factorial design for 3 -factors where these factors and their response variables are analyze by creating different models, graphs, coefficients and equations. That is why these design methods are applicable and are carried out with the help of Minitab software. Full factorial design has been carried out one by one for two different types of pipes i.e. 3-feet, 4-feet.

\section{A. $2^{3}$ Factorial Design for 3 Feet Size Pipe}

\section{1) Design Model:}

Factors 3

Replicates 2

Base runs 8

Total runs $\quad 16$

Total Blocks 1

Levels

$2,2,2$

The design table IV and V shows the experimental conditions or setting for each of the factors for the design points using coded factors names and levels.

Table IV. Design table showing experimental settings for factors

\begin{tabular}{|c|c|c|c|c|}
\hline Run & Blocks & Pressure (A) & Temperature (B) & Cooling Temp. (C) \\
\hline $\mathbf{1}$ & 1 & -1 & -1 & -1 \\
\hline $\mathbf{2}$ & 1 & -1 & -1 & 1 \\
\hline $\mathbf{3}$ & 1 & -1 & 1 & -1 \\
\hline $\mathbf{4}$ & 1 & -1 & 1 & 1 \\
\hline $\mathbf{5}$ & 1 & 1 & -1 & -1 \\
\hline $\mathbf{6}$ & 1 & 1 & -1 & 1 \\
\hline $\mathbf{7}$ & 1 & 1 & 1 & -1 \\
\hline $\mathbf{8}$ & 1 & 1 & 1 & 1 \\
\hline $\mathbf{9}$ & 1 & -1 & -1 & -1 \\
\hline $\mathbf{1 0}$ & 1 & -1 & -1 & 1 \\
\hline $\mathbf{1 1}$ & 1 & -1 & 1 & -1 \\
\hline $\mathbf{1 2}$ & 1 & -1 & 1 & 1 \\
\hline $\mathbf{1 3}$ & 1 & 1 & -1 & -1 \\
\hline $\mathbf{1 4}$ & 1 & 1 & -1 & -1 \\
\hline $\mathbf{1 5}$ & 1 & 1 & 1 & 1 \\
\hline $\mathbf{1 6}$ & 1 & 1 & 1 & \\
\hline
\end{tabular}

With 3 factors that each have 2 levels, the design has 16 runs. In the worksheet, the Minitab displays the names of the factors and the names of the levels. Because the experimenter created a full factorial design, the experimenter can estimate all of the interactions among the factors.

Table V. Levels of all factors

\begin{tabular}{|c|c|c|c|}
\hline S. No & Factors & Level (-1) & Level (+1) \\
\hline $\mathbf{1}$ & Pressure $(\mathrm{MPa})$ & 0.40 & 0.42 \\
\hline $\mathbf{2}$ & Temperature $\left({ }^{\circ} \mathrm{C}\right)$ & 220 & 235 \\
\hline $\mathbf{3}$ & Cooling Temperature $\left({ }^{\circ} \mathrm{C}\right)$ & 5 & 9 \\
\hline
\end{tabular}

Each time when a design is created, Minitab reserves and names the following columns as shown in table VI.

- $\quad$ C1 (Std Order) stores the standard order.

- $\quad$ C2 (Run Order) stores run order. 
- $\quad$ C3 (Cenetr Pt or Pt Type) stores the point type. If you create a 2-level design, Minitab names this column Center Pt. If you create a Plackett-Burman or general full factorial design, Minitab names this column Pt Type. The codes are: 0 is a center point run and 1 is a corner point

- $\quad$ C4 (Blocks) stores the blocking variable. When the design is not blocked, Minitab sets all column values to 1. And C5-Cn stores the factors/components. Minitab stores each factors in your design in a separate column.

Table VI. Factorial design store information

\begin{tabular}{|c|c|c|c|c|c|c|l|}
\hline Std Order & Run Order & Center Type & Blocks & Pressure & Temperature & $\begin{array}{c}\text { Cooling } \\
\text { Temp. }\end{array}$ & Response \\
\hline $\mathbf{1 2}$ & 1 & 1 & 1 & 0.40 & 235 & 5 & 3.800 \\
\hline $\mathbf{6}$ & 2 & 1 & 1 & 0.40 & 220 & 9 & 3.790 \\
\hline $\mathbf{9}$ & 3 & 1 & 1 & 0.40 & 235 & 5 & 3.980 \\
\hline $\mathbf{1 1}$ & 4 & 1 & 1 & 0.40 & 220 & 5 & 3.960 \\
\hline $\mathbf{8}$ & 5 & 1 & 1 & 0.42 & 235 & 9 & 3.830 \\
\hline $\mathbf{7}$ & 6 & 1 & 1 & 0.40 & 235 & 9 & 3.760 \\
\hline $\mathbf{2}$ & 7 & 1 & 1 & 0.40 & 220 & 9 & 3.690 \\
\hline $\mathbf{1 4}$ & 8 & 1 & 1 & 0.42 & 220 & 9 & 4.000 \\
\hline $\mathbf{3}$ & 9 & 1 & 1 & 0.42 & 220 & 5 & 3.890 \\
\hline $\mathbf{1 5}$ & 10 & 1 & 1 & 0.42 & 220 & 9 & 3.810 \\
\hline $\mathbf{5}$ & 11 & 1 & 1 & 0.40 & 235 & 9 & 3.940 \\
\hline $\mathbf{1 0}$ & 12 & 1 & 1 & 0.42 & 220 & 5 & 3.970 \\
\hline $\mathbf{1 3}$ & 13 & 1 & 1 & 0.42 & 235 & 5 & 3.670 \\
\hline $\mathbf{1}$ & 14 & 1 & 1 & 0.42 & 235 & 9 & 3.560 \\
\hline $\mathbf{1 6}$ & 15 & 1 & 1 & 0.40 & 220 & 5 & 3.712 \\
\hline $\mathbf{4}$ & 16 & 1 & 1 & 0.42 & 235 & 5 & 3.699 \\
\hline
\end{tabular}

This table shows the design of experiment which consist of three factors as pressure, temperature and cooling temperature with their low and high levels values. There are 8 runs for each replication and it is replicated twice and each runs is perform randomly with different combinations of values for three factors and obtained the specific response for each runs of experimental design.

2) Results and Analysis:

Resulted values for Fit and Residuals are provided in table VII.

Table VII. Resulted values for fits and residuals

\begin{tabular}{|c|c|c|}
\hline Response & Fits & Residuals \\
\hline 3.800 & 3.8900 & -0.0900 \\
\hline 3.790 & 3.7400 & 0.0500 \\
\hline 3.980 & 3.8900 & 0.0900 \\
\hline 3.960 & 3.8360 & 0.1240 \\
\hline 3.830 & 3.6950 & 0.1350 \\
\hline 3.760 & 3.8500 & -0.0900 \\
\hline 3.690 & 3.7400 & -0.0500 \\
\hline 4.000 & 3.9050 & 0.0950 \\
\hline 3.890 & 3.9300 & -0.0400 \\
\hline 3.810 & 3.9050 & -0.0950 \\
\hline 3.940 & 3.8500 & 0.0900 \\
\hline 3.970 & 3.9300 & 0.0400 \\
\hline 3.670 & 3.6845 & -0.0145 \\
\hline 3.560 & 3.6950 & -0.1350 \\
\hline 3.712 & 3.8360 & -0.1240 \\
\hline 3.699 & 3.6845 & 0.0145 \\
\hline
\end{tabular}


In the above table, first column shows the response values for weight of the pipes, next column represent fits values for a given response value and third or last column shows the residuals values which represent the dissimilarity between experimental value and expected value of the response variable.

\section{3) General Factorial Regressions:}

\begin{tabular}{|c|c|c|}
\hline Factors & & \\
\hline Pressure & 2 & $0.40,0.42$ \\
\hline Temperature & 2 & 220,2350 \\
\hline Cooling Temperature & 2 & 5,9 \\
\hline
\end{tabular}

After studying the design, you indicate to apt the model by counting all key effects $(\mathrm{A}, \mathrm{B}, \mathrm{C})$ and all interface terms (AB, AC, BC, ABC) as shown in table VIII. The subsequent ANOVA tables gives the values for the SS values and MS values for residual error, all $\mathrm{F}$ statistics, and all $\mathrm{p}$-values.

Table VIII. Analysis of Variance table

\begin{tabular}{|c|c|c|c|c|c|}
\hline Source & DF & Adj SS & Adj MS & F-Value & P-Value \\
\hline Model & 7 & 0.131315 & 0.018759 & 1.19 & 0.403 \\
\hline Linear & 3 & 0.029481 & 0.009827 & 0.62 & 0.620 \\
\hline $\mathbf{A}$ & 1 & 0.002576 & 0.002576 & 0.16 & 0.697 \\
\hline $\mathbf{B}$ & 1 & 0.021243 & 0.021243 & 1.35 & 0.279 \\
\hline $\mathbf{C}$ & 1 & 0.005663 & 0.005663 & 0.36 & 0.566 \\
\hline 2-Way Interactions & 3 & 0.101729 & 0.033910 & 2.15 & 0.172 \\
\hline $\mathbf{A * B}$ & 1 & 0.095945 & 0.095945 & 6.08 & 0.039 \\
\hline $\mathbf{A * C}$ & 1 & 0.003691 & 0.003691 & 0.23 & 0.642 \\
\hline $\mathbf{B * C}$ & 1 & 0.002093 & 0.002093 & 0.13 & 0.725 \\
\hline 3-Way Interactions & 1 & 0.000105 & 0.000105 & 0.01 & 0.937 \\
\hline $\mathbf{A * B * C}$ & 1 & 0.000105 & 0.000105 & 0.01 & 0.937 \\
\hline Error & 8 & 0.126272 & 0.015784 & & \\
\hline Total & 15 & 0.257587 & & & \\
\hline
\end{tabular}

Individual value in the Adj MS column is premeditated by dividing the values in the Adj SS column by the equivalent values in the DF column (Adj MS for factors A= Adj SS / DF =0.002576 / $1=0.002576$ ). But the Adj MS for residuals blunder, randomly mentioned to as the mean square of the error (MSE) is premeditated in the same way as for the factor A. Additionally, Minitab analyzes each value in the tables F column by dividing each Adj MS value by the MSE. For example, the F-value for factor A would equal 0.0676 / MSE and finally, the Pvalue is premeditated from the F-statistic. The analysis of variance tables provides a summary of key effects and interaction among those three factors which are 'pressure', 'temperature' and 'cooling temperature'. After that beholding at the p-values in the table to determine whether or not there are any substantial effects at $95 \%$ confidence level i.e. Alpha 0.05

The result show that key effects and interaction effects both are substantial as p-value (0.039) the main effect which is for pressure \& temperature and less than alpha value of $(0.05)$. The three way interaction have no significant effects. The table IX shows the value of R-square $50.98 \%$ which is quite enough to fit our data and it shows the percentage of variation covered by factors i.e. pressure, temperature and cooling temperature.

Table IX. Percentage of variation covered by factors

\begin{tabular}{|l|c|c|}
\hline S & R-sq & R-sq(adj) \\
\hline 0.125635 & $50.98 \%$ & $8.09 \%$ \\
\hline
\end{tabular}

$\mathrm{R}$-square is the proportion of deviation in the response that is described by the model. It is intended as 1 minus ratio of the error sum of squares (which is the deviation that is not described by model) to the total sum of squares (which is the total variation in the model). Use R-sq to define how well the model outbursts your data. The higher the R-sq value, the superior the model fits your data. R-sq is permanently between $0 \%$ and $100 \%$. In our circumstance, its value is $50.98 \%$ which indicate that larger part of the variability of the response data around its mean is explained. 
Table X. Coded Coefficient for all factors

\begin{tabular}{|l|l|l|l|l|}
\hline Term & \multicolumn{1}{|c|}{ Coef } & SE Coef & T-Value & P-Value \\
\hline Constant & 3.8163 & 0.0314 & 121.51 & 0.000 \\
\hline Pressure & 0.0127 & 0.0314 & 0.40 & 0.697 \\
\hline Temperature & 0.0364 & 0.0314 & 1.16 & 0.279 \\
\hline Cooling Temp. & 0.0188 & 0.0314 & 0.60 & 0.566 \\
\hline Pressure*Temperature & -0.0774 & 0.0314 & -2.47 & 0.039 \\
\hline Pressure*Cooling Temperature & 0.0152 & 0.0314 & 0.48 & 0.642 \\
\hline Temperature*Cooling Temperature & 0.0114 & 0.0314 & 0.36 & 0.725 \\
\hline Pressure*Temperature*Cooling Temp. & 0.0026 & 0.0314 & 0.08 & 0.937 \\
\hline
\end{tabular}

You apt the complete model, which comprises the three main effects, the 2-way interaction and 3-way interaction as shown in table X. Effects are statistically substantial when their p-values in the coded coefficients tables are less than alpha.

\section{4) Regression Equation:}

$$
\text { Response }=3.8163+0.0127 \mathrm{~A}+0.0364 \mathrm{~B}+0.0188 \mathrm{C}
$$

This is the required equation which will provide optimum value for response variable.

5) Residual Plots:

A residual plot is a display that is used to inspect the goodness-of-fit in regression and ANOVA. Inspecting residual plots helps you control whether the ordinary least squares assumptions are being lit. Minitab provides the residual plots as shown in figure 2 .

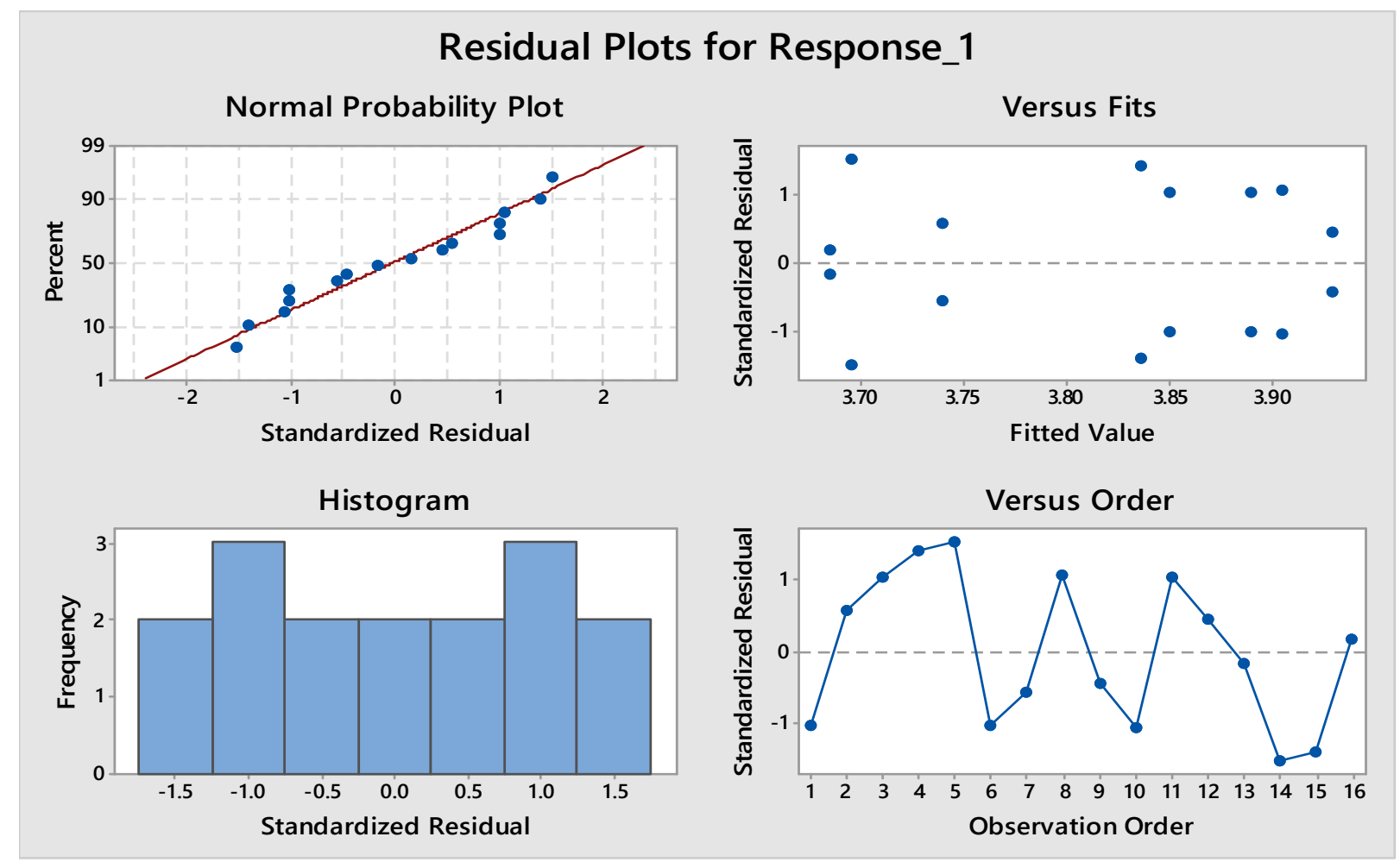

Fig. 2. Residual plots for response

\section{- Normal Probability Plot and Histogram of Residual}

The normal probability plot in figure 2 shows that the residuals are scattered normally around a straight line and follow reasonably the straight line. Also in the same figure a histogram shows that the residual forms a normal distribution centered at zero. Keeping in view the centered zero of histogram and values closed to the straightforward line is standard possibility plan, normality assumption of the residual is satisfied. 
- $\quad$ Residual versus Order of Data

As the graph of the observation order in figure 2 shows that the points are randomly scattered around a center line. Hence, showing that there is no motive to uncertain any violation of independency statement. This shows that values are independent of each other's.

\section{- $\quad$ Residual verses Fitted Values}

The graph of fitted values in figure 2 shows that the data points are scattered randomly around a straight line. It is clear that there is no skewness or data is dumbed at one side and form a recognizable pattern around a straight line hence clear that there is no constant variation in data.

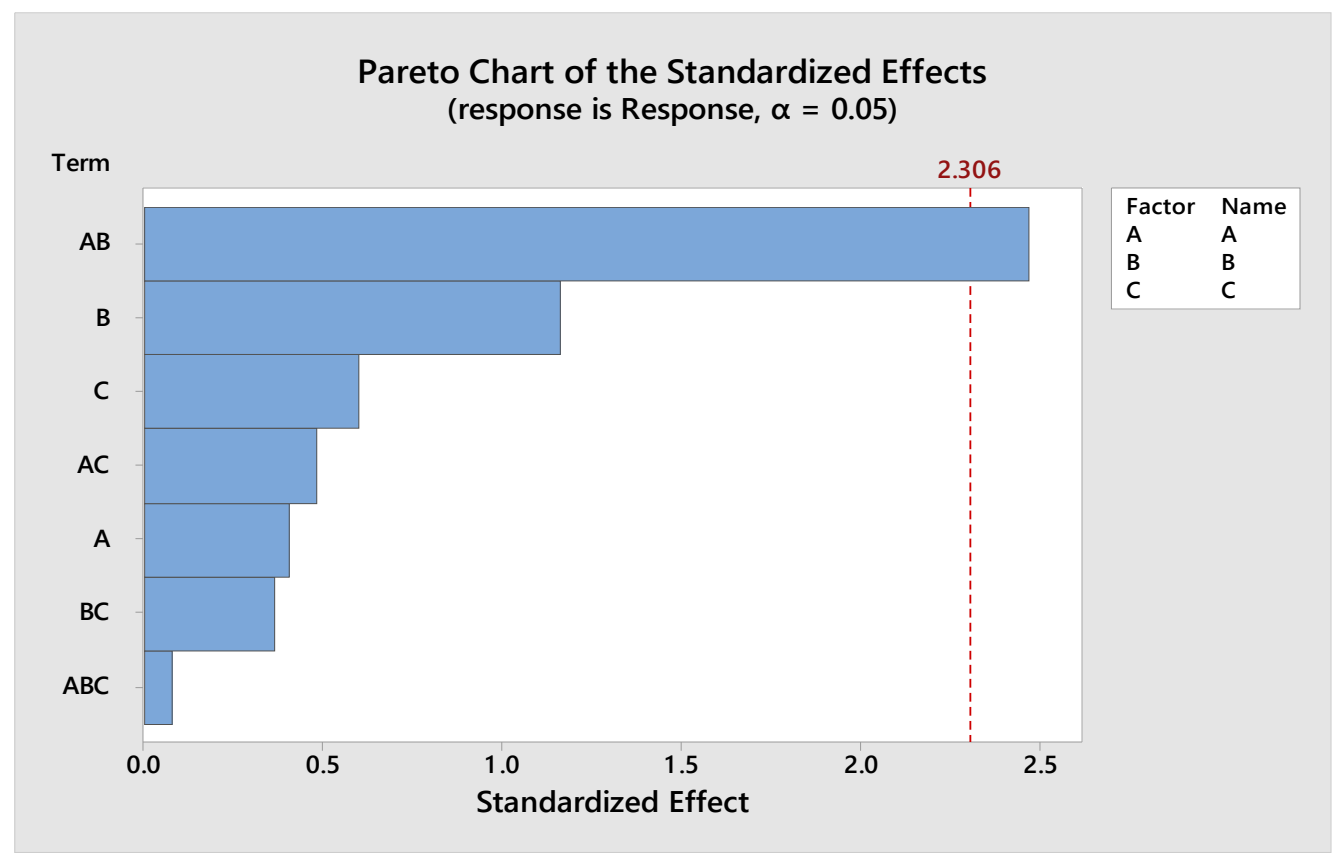

Fig. 3. Pareto Chart for standardized effect

Minitab shows the absolute value of the effects on the Pareto chart as shown in figure 3 . Any effects that spread elsewhere the reference line are momentous. Pressure and Temperature (AB) is significant.

\section{6) Interpret the Factorial Plots:}

The factorial plots includes all the main effects plot and the interaction plot. A main effect is the difference in the mean response between two levels of a factor. The main effect plot show the mean for response using both level of pressure, the means for response using both levels of temperature and the mean for response using both levels of cooling temperature as shown in figure 4 . The interaction plot shows the impact of all three factors which are temperature, pressure and cooling temperature on the response. Because an interaction means that the effect of one factor depend on the level of other factor, assessing interactions are important. 


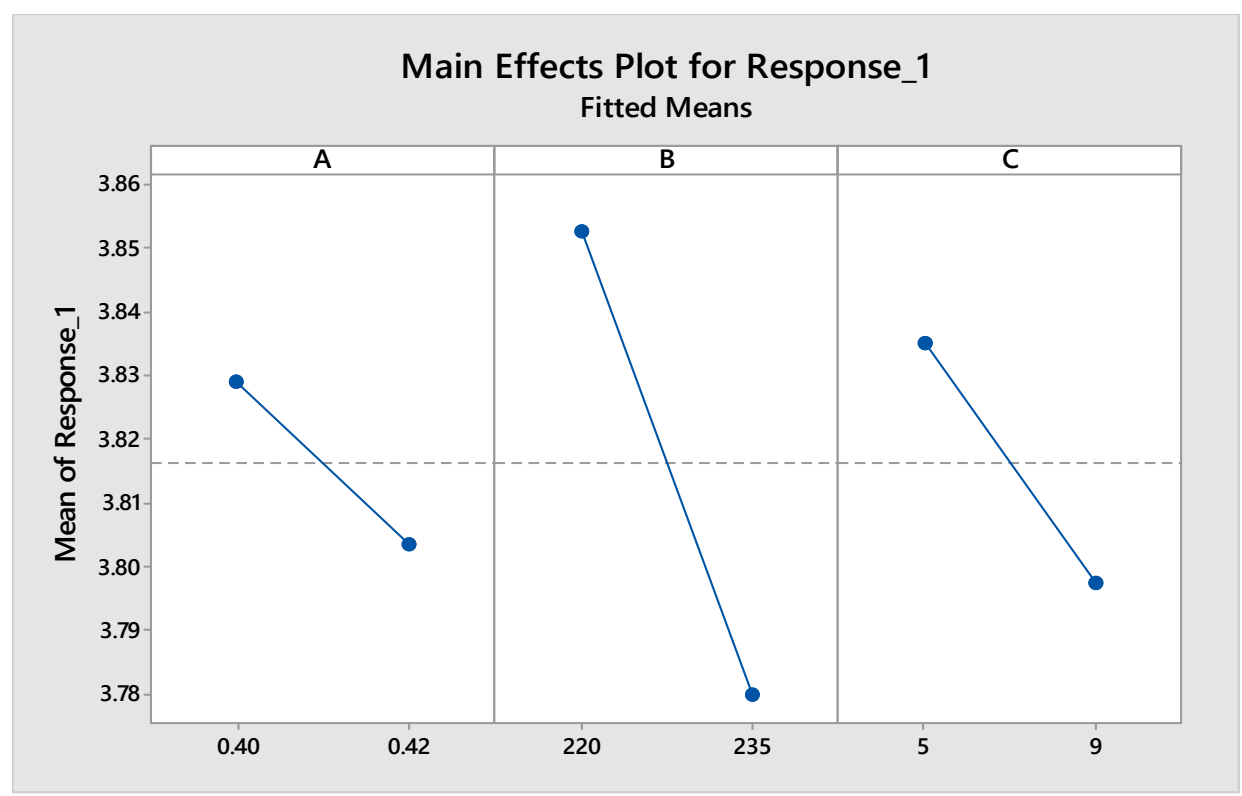

Fig. 4. Main effects plots for response

Each point represents the mean response for one level of a factor. The horizontal central line shows the mean response value for all runs. The left panel of the plot indicates that response obtained using 0.42 value of pressure small deviation from mean than the response obtained using 0.42 value of pressure. The middle panel of the plot indicates that response value obtained using 220 temperature is more deviated from than the mean that were obtained using 235 temperature and the right panel of the plot indicates the response value obtained using 5 value of cooling temperature is less deviated than that were obtained using 9 cooling temperature.

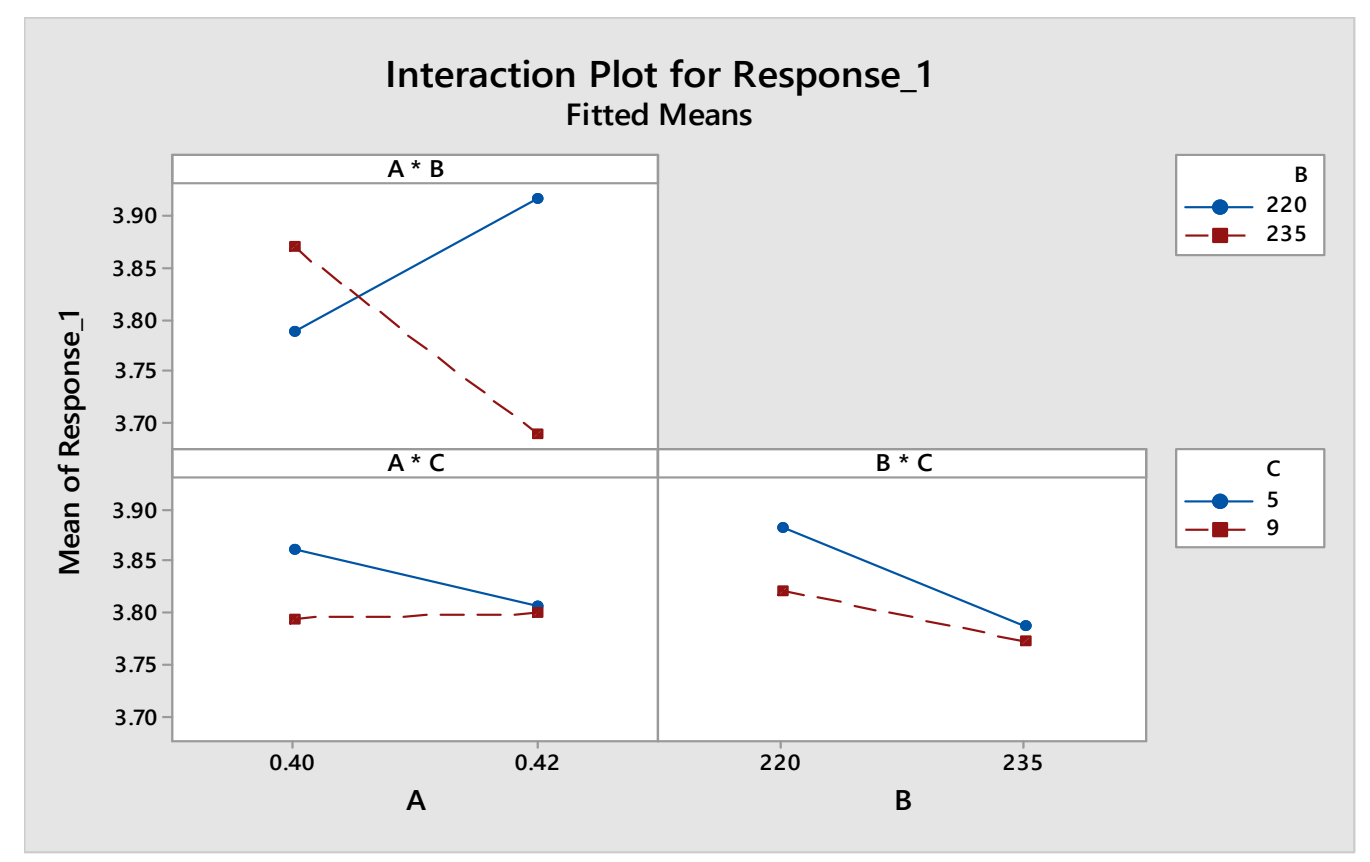

Fig. 5. Interaction plot for response

Each point in the interaction plots shows the mean response value at different combinations of factors levels as shown in figure 5. If the lines are parallel to each other, it means there is no interaction but if the line are not parallel to each other, then the plot indicates that there is an interaction between the two factors. The interaction plot indicates that response value for weight of the pipes that observed using the pressure 0.40 and temperature 220 is more close to mean value of weight of polypropylene pipes. Orders that were observed using the pressure 0.42 and temperature 235 too much far away from mean value. We conclude that the pressure 0.40 has greater effect when temperature 220 is used instead of 235 . 


\section{7) Variable setting:}

The table XI and XII displays the model equation and the variable settings. The fitted value (also called predicted values) for these setting is $3.890 \mathrm{~g}$. However, all estimates contain uncertainty because they use sample data. The $95 \%$ confidence interval is the range of likely values for mean response value.

Table XI. Optimize value for factors

\begin{tabular}{|c|c|}
\hline $\mathrm{A}$ & 0.40 \\
\hline $\mathrm{B}$ & 235 \\
\hline $\mathrm{C}$ & 5 \\
\hline
\end{tabular}

Table XII. Setting variable for 3-feet size pipe

\begin{tabular}{|l|l|l|l|}
\hline Fit & SE Fit & 95\% CI & 95\%PI \\
\hline 3.8900 & 0.0888 & $(3.6851,4.0949)$ & $(3.5352,4.2448)$ \\
\hline
\end{tabular}

If you use the pressure value of 0.40 , temperature value of 235 and cooling temperature 5 , you can $95 \%$ confident that the mean response value which weight will be between 3.699 and 4.109 grams.

B. $2^{3}$ Factorial Design for 4 Feet Size Pipe

1) Design Model:

Factors 3

Replicates $\quad 2$

Base runs 8

Total runs $\quad 16$

Total Blocks 1

Levels

Table XIII shows the design of experiment which consist of three factors as pressure, temperature and cooling temperature with their low and high level values.

Table XIII. Factorial Design Store Information

\begin{tabular}{|c|c|c|c|c|c|c|c|}
\hline StdOrder & RunOrder & CenterType & Blocks & Pressure & Temperature & $\begin{array}{c}\text { Cooling } \\
\text { Temp. }\end{array}$ & Response \\
\hline $\mathbf{1 2}$ & 1 & 1 & 1 & 0.40 & 235 & 9 & 6.09 \\
\hline $\mathbf{6}$ & 2 & 1 & 1 & 0.42 & 235 & 9 & 5.78 \\
\hline $\mathbf{9}$ & 3 & 1 & 1 & 0.40 & 220 & 5 & 5.98 \\
\hline $\mathbf{1 1}$ & 4 & 1 & 1 & 0.42 & 235 & 5 & 5.89 \\
\hline $\mathbf{8}$ & 5 & 1 & 1 & 0.40 & 235 & 5 & 5.81 \\
\hline $\mathbf{7}$ & 6 & 1 & 1 & 0.40 & 235 & 5 & 5.90 \\
\hline $\mathbf{2}$ & 7 & 1 & 1 & 0.42 & 220 & 9 & 6.05 \\
\hline $\mathbf{1 4}$ & 8 & 1 & 1 & 0.40 & 220 & 9 & 6.15 \\
\hline $\mathbf{3}$ & 9 & 1 & 1 & 0.42 & 235 & 9 & 5.77 \\
\hline $\mathbf{1 5}$ & 10 & 1 & 1 & 0.40 & 235 & 9 & 5.82 \\
\hline $\mathbf{5}$ & 11 & 1 & 1 & 0.40 & 220 & 5 & 5.87 \\
\hline $\mathbf{1 0}$ & 12 & 1 & 1 & 0.42 & 235 & 5 & 5.92 \\
\hline $\mathbf{1 3}$ & 13 & 1 & 1 & 0.42 & 220 & 5 & 6.18 \\
\hline $\mathbf{1}$ & 14 & 1 & 1 & 0.42 & 220 & 9 & 5.96 \\
\hline $\mathbf{1 6}$ & 15 & 1 & 1 & 0.42 & 220 & 5 & 5.99 \\
\hline $\mathbf{4}$ & 16 & 1 & 1 & 0.40 & 220 & 9 & 6.01 \\
\hline
\end{tabular}

There are 8 runs for each replication and it is replicated twice and each runs is perform randomly with different combinations of values for three factors and obtained the specific response for each runs of experimental design.

2) Results and Analysis:

Resulted values for Fit and Residuals are provided in table XIV. 
Table XIV. Resulted values for fit and residuals

\begin{tabular}{|c|c|c|}
\hline Response & Fits & Residuals \\
\hline 6.09 & 5.9550 & 0.1350 \\
\hline 5.78 & 5.7750 & 0.0050 \\
\hline 5.98 & 5.9250 & 0.0550 \\
\hline 5.89 & 5.9050 & -0.0150 \\
\hline 5.81 & 5.8550 & -0.0450 \\
\hline 5.90 & 5.8550 & 0.0450 \\
\hline 6.05 & 6.0075 & 0.0425 \\
\hline 6.15 & 6.0825 & 0.0675 \\
\hline 5.77 & 5.7750 & -0.0050 \\
\hline 5.82 & 5.9550 & -0.1350 \\
\hline 5.87 & 5.9250 & -0.0550 \\
\hline 5.92 & 5.9050 & 0.0150 \\
\hline 6.18 & 6.0850 & 0.0950 \\
\hline 5.96 & 6.0075 & -0.0425 \\
\hline 5.99 & 6.0850 & -0.0950 \\
\hline 6.01 & 6.0825 & -0.0675 \\
\hline
\end{tabular}

In the above table, first column shows the response values for Weight of the pipes, next column represent fits values for a given response value and third or last column shows the residuals values which represent the difference between observed value and predicted value of the response variable.

3) General Factorial Regressions:

Factors Levels Values

$\begin{array}{lll}\text { Pressure } & 2 & 0.40,0.42 \\ \text { Temperature } & 2 & 220,235 \\ \text { Cooling Temperature } & 2 & 5,9\end{array}$

When analyzing the design, you choose to fit the model by including all main effects $(\mathrm{A}, \mathrm{B}, \mathrm{C})$ and all interaction terms (AB, AC, BC, ABC) as shown in table XV. The resulting ANOVA tables gives the values for the SS values and MS values for residual error, all F statistics, and all p-values.

Table XV. Analysis of variance table

\begin{tabular}{|c|c|c|c|c|c|}
\hline Source & DF & Adj SS & Adj MS & F-Value & P-Value \\
\hline Model & 7 & 0.162800 & 0.023257 & 2.39 & 0.123 \\
\hline Linear & 3 & 0.094156 & 0.031385 & 3.23 & 0.082 \\
\hline $\mathbf{A}$ & 1 & 0.000506 & 0.000506 & 0.05 & 0.825 \\
\hline $\mathbf{B}$ & 1 & 0.093025 & 0.093025 & 9.56 & 0.015 \\
\hline $\mathbf{C}$ & 1 & 0.000625 & 0.000625 & 0.06 & 0.806 \\
\hline 2-Way Interactions & 3 & 0.068637 & 0.022879 & 2.35 & 0.148 \\
\hline $\mathbf{A * B}$ & 1 & 0.011556 & 0.011556 & 1.19 & 0.307 \\
\hline $\mathbf{A * C}$ & 1 & 0.054056 & 0.054056 & 5.56 & 0.046 \\
\hline $\mathbf{B}$ C & 1 & 0.003025 & 0.003025 & 0.31 & 0.592 \\
\hline 3-Way Interactions & 1 & 0.000006 & 0.000006 & 0.00 & 0.980 \\
\hline A*B*C & 1 & 0.000006 & 0.000006 & 0.00 & 0.980 \\
\hline Error & 8 & 0.077825 & 0.009728 & & \\
\hline
\end{tabular}

The analysis of variance tables gives a summary of main effects and interaction among those three factors which are 'Pressure', 'Temperature' and 'Cooling Temperature'. After that looking at the p-values in the table to determine whether or not there are any significant effects at $95 \%$ confidence level i.e. Alpha 0.05 
Table XVI. Percentage of variation covered by factors

\begin{tabular}{|l|c|c|}
\hline S & R-sq & R-sq(adj) \\
\hline 0.0986313 & $67.66 \%$ & $39.36 \%$ \\
\hline
\end{tabular}

The result shows in table XVI that main effects and interaction effects both are significant as p-value $(0.015)$ and $(0.46)$ the main effect which is for temperature (B) \& pressure and cooling temperature (AC) respectively and less than alpha value of (0.05). The three way interaction have no significant effects. The value of R-square $67.66 \%$ as shown in table 16 is quite enough to fit our data and it shows the percentage of variation covered by factors i.e. Pressure, Temperature and Cooling Temperature.

Table XVII. Coded coefficient for all factors

\begin{tabular}{|l|r|r|r|r|}
\hline \multicolumn{1}{|c|}{ Term } & Coef & SE Coef & T-Value & P-Value \\
\hline Constant & 5.9488 & 0.0247 & 241.25 & 0.000 \\
\hline Pressure & 0.0056 & 0.0247 & 0.23 & 0.825 \\
\hline Temperature & 0.0763 & 0.0247 & 3.09 & 0.015 \\
\hline Cooling Temp. & -0.0062 & 0.0247 & -0.25 & 0.806 \\
\hline Pressure*Temperature & -0.0269 & 0.0247 & -1.09 & 0.307 \\
\hline Pressure*Cooling Temperature & -0.0581 & 0.0247 & -2.36 & 0.046 \\
\hline Temperature*Cooling Temp. & -0.0137 & 0.0247 & -0.56 & 0.592 \\
\hline Pressure*Temperature*Cooling Temp. & -0.0006 & 0.0247 & -0.03 & 0.980 \\
\hline
\end{tabular}

You fit the complete model, which includes the three main effects, the 2-way interaction and 3-way interaction as shown in table XVII. Effects are statistically significant when their p-values in the coded coefficients tables are less than alpha. At the default alpha of 0.05 , the following are significant:

- The main effects for the Temperature represented by ' $\mathrm{B}$ ' and $\mathrm{p}$-value is $(0.015)$

- The main effects for the Pressure and Cooling Temperature represented by 'A' and p-value is $(0.046)$

4) Regression Equation:

$$
\text { Response }=5.9488+0.0056 \mathrm{~A}+0.0763 \mathrm{~B}-0.0062 \mathrm{C}
$$

This is the required equation which will give optimum value for Response variable.

5) Residual Plots:

A residual plot is a displays that is used to observe the goodness-of-fit in regression and ANOVA. Inspecting residual plots helps you regulate whether the ordinary least squares assumptions are being met. Minitab provides the residual plots as shown in figure 6. 


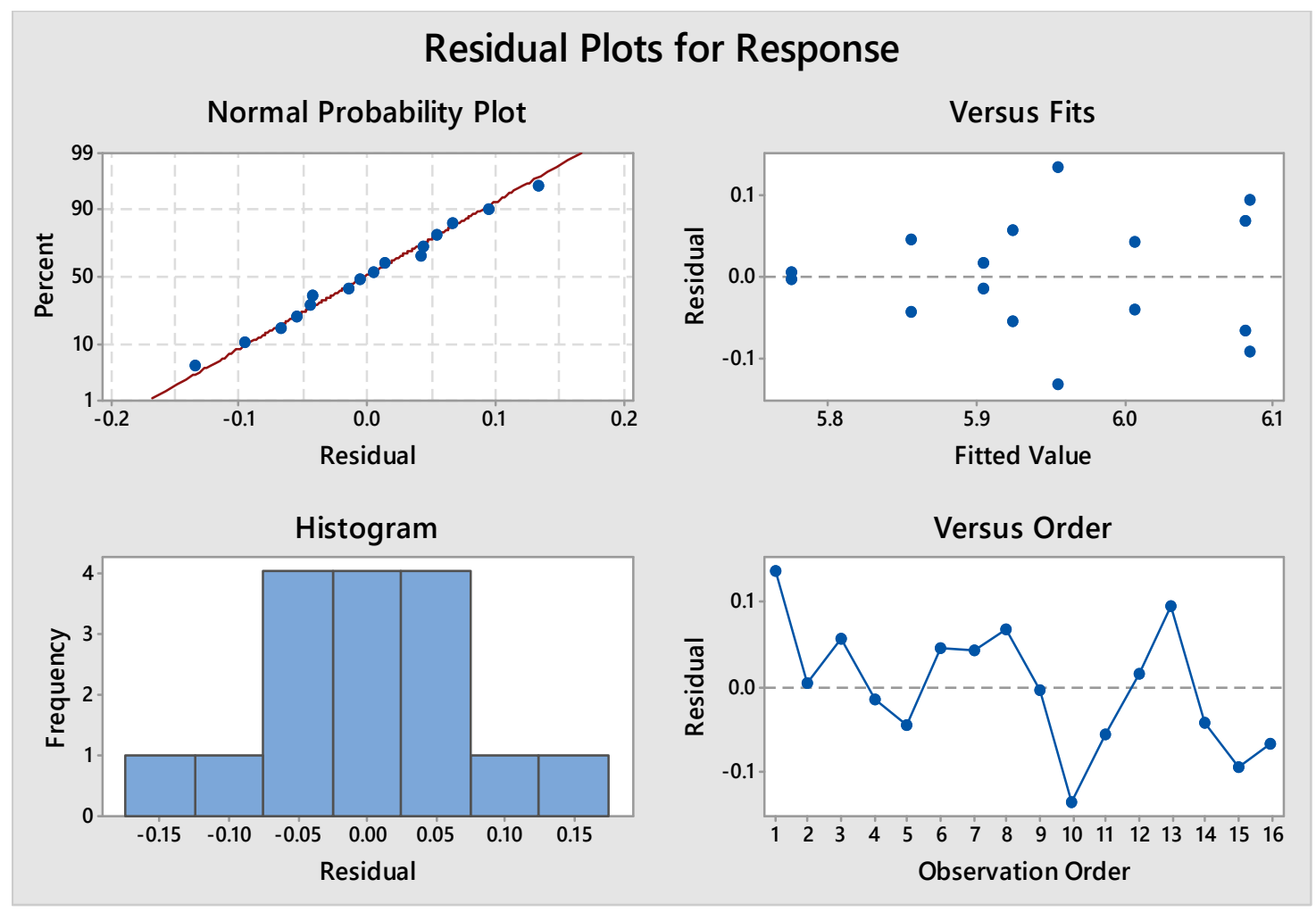

Fig. 6. Residual plots for response

- $\quad$ Normal Probability Plot and Histogram of Residual

The normal probability plot in figure 6 shows that the residuals are scattered normally around a straight line and follow reasonably the straight line. Also in the same Fig. a histogram shows that the residual forms a normal distribution centered at zero. Keeping in view the centered zero of histogram and values closed to the straight line is normal probability plot, normality assumption of the residual is satisfied.

\section{- $\quad$ Residual versus Order of Data}

As the graph of the observation order in figure 6 shows that the points are randomly scattered around a center line. Hence, showing that there is no reason to suspect any violation of independency assumption. This shows that values are independent of each other's.

- $\quad$ Residual verses Fitted Values

The graph of fitted values in figure 6 shows that the data points are scattered randomly around a straight line. It is clear that there is no skewness or data is dumbed at one side and form a recognizable pattern around a straight line hence clear that there is no constant variation in data. 


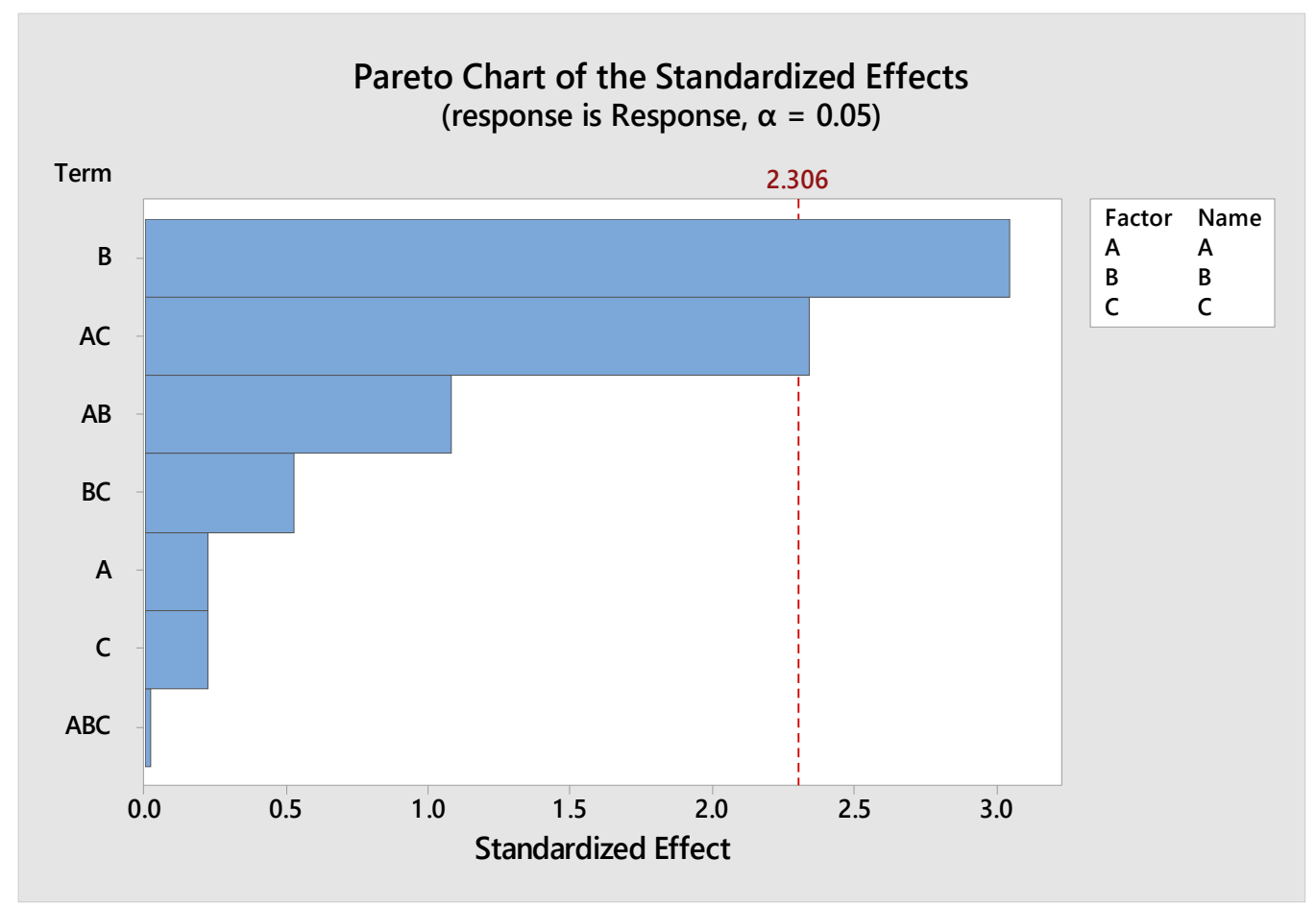

Fig. 7. Pareto Chart for standardized effect

Minitab shows the absolute value of the effects on the Pareto chart as shown in figure 7. Any effects that spread elsewhere the reference line are momentous. Pressure and Temperature $(A B)$ is significant.

6) Interpret the Factorial Plots:

The factorial plots includes all the main effects plot and the interaction plot. A main effect is the difference in the mean response between two levels of a factor. The main effect plot show the mean for response using both level of pressure, the means for response using both levels of temperature and the mean for response using both levels of cooling temperature. The interaction plot in figure 7 shows the impact of all three factors which are temperature, pressure and cooling temperature on the response. Because an interaction means that the effect of one factor depend on the level of other factor, assessing interactions are important.

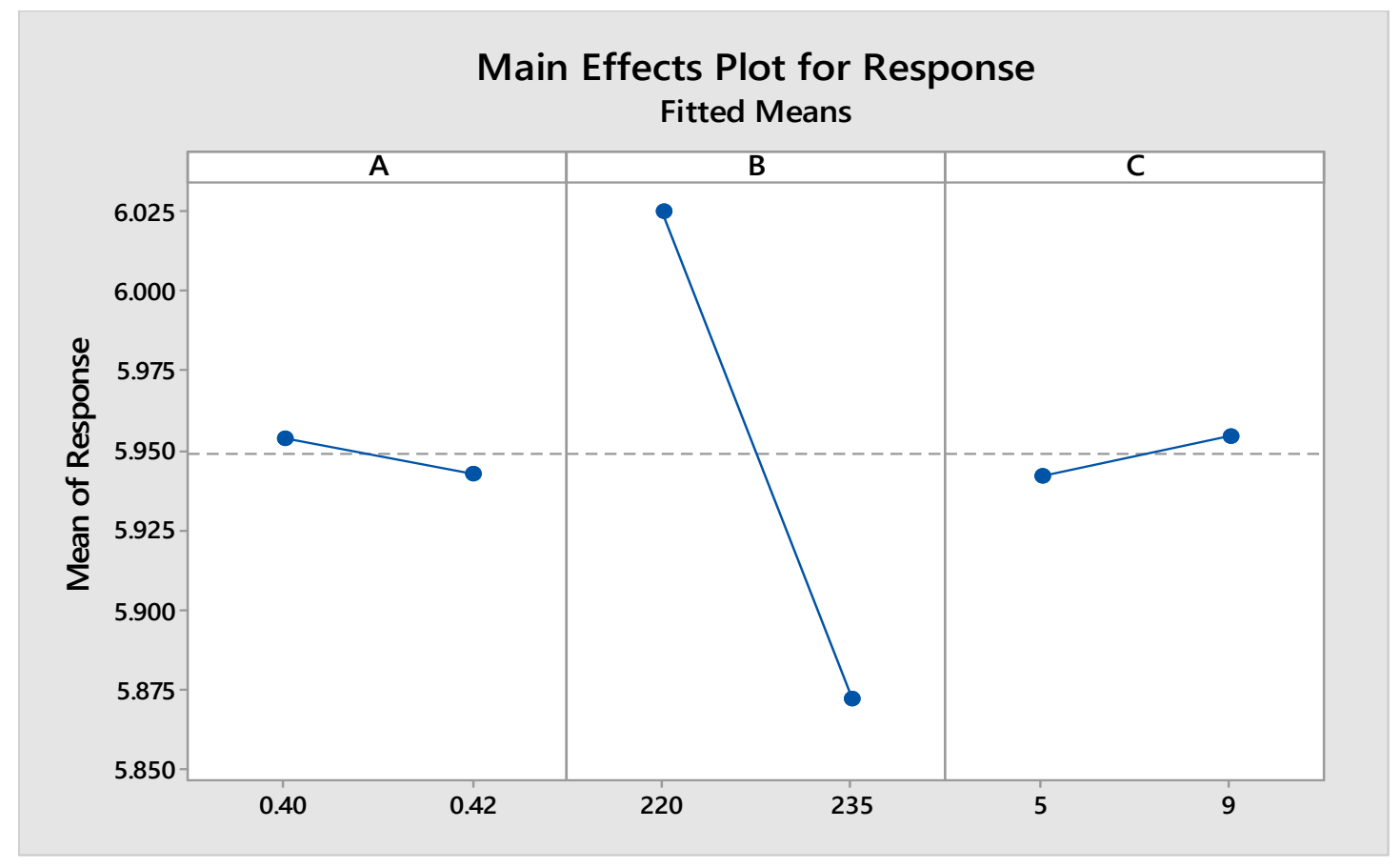

Fig. 8. Main effects plots for response 
Each point represents the mean response for one level of a factor. The horizontal central line shows the mean response value for all runs. The left panel of the plot indicates that response obtained using 0.42 value of pressure small deviation from mean than the response obtained using 0.42 value of pressure. The middle panel of the plot indicates that response value obtained using 220 temperature is much more deviated from than the mean that were obtained using 235 temperature and the right panel of the plot indicates the response value obtained using 5 value of cooling temperature is less deviated than that were obtained using 9 cooling temperature.

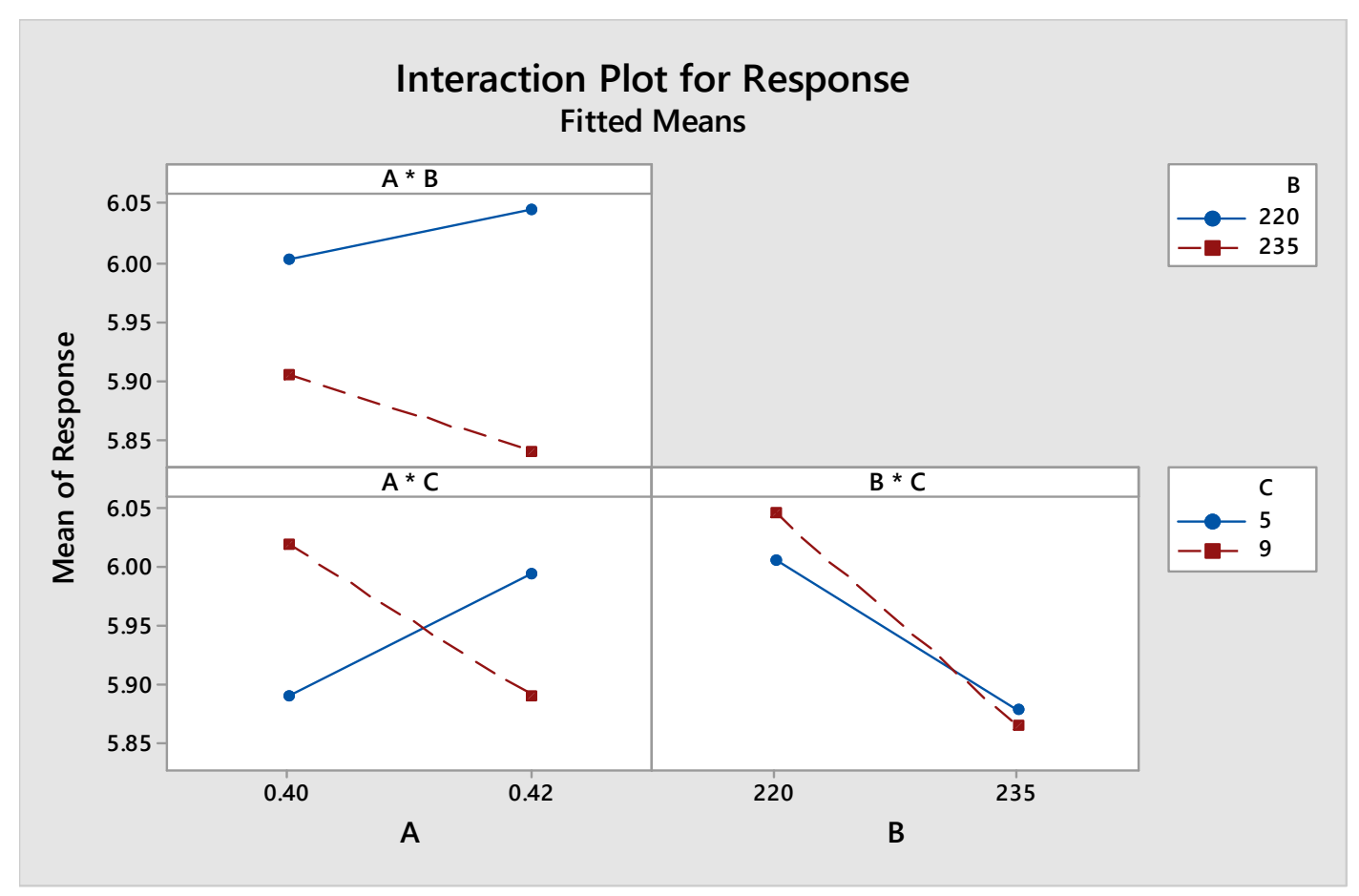

Fig. 9. Interaction plot for response

Each point in the interaction plots shows the mean response value at different combinations of factors levels as shown in figure 8. If the lines are parallel to each other, it means there is no interaction but if the line are perpendicular or intersecting each other, then the plot indicates that there is an interaction between the two factors. The interaction plot $\left(\mathrm{A}^{*} \mathrm{C}\right)$ indicates that response value for weight of the pipes that observed using the pressure 0.42 and cooling temperature 5 is more close to mean value of weight of polypropylene pipes. Orders that were observed using the pressure 0.40 and cooling temperature 9 are too much far away from mean value. We conclude that the pressure 0.42 has greater effect when temperature 5 is used.

\section{7) Variable setting:}

The tables XVIII and XIX shows the model equation and the variable settings. The fitted value for these setting is $5.9050 \mathrm{~g}$. All estimates contain uncertainty because they use sample data. The $95 \%$ confidence interval is the range of likely values for mean response value.

Table XVIII. Optimize value for factors

\begin{tabular}{|c|c|}
\hline $\mathrm{A}$ & 0.42 \\
\hline $\mathrm{B}$ & 235 \\
\hline $\mathrm{C}$ & 5 \\
\hline
\end{tabular}

Table XIX. Setting variable for 4-feet size pipe

\begin{tabular}{|l|l|l|l|}
\hline Fit & SE Fit & 95\% CI & 95\%PI \\
\hline 5.9050 & 0.0697 & $(5.7442,6.0658)$ & $(5.6264,6.1836)$ \\
\hline
\end{tabular}

If you use the pressure value of 0.42 , temperature value of 235 and cooling temperature 5 , you can $95 \%$ confident that the mean response value which weight will be between 5.744 and $6.066 \mathrm{~g}$. 


\section{CONCLUSION}

Three parameters i.e. temperature, pressure and cooling temperature were considered the main critical factors which can affect the process. Based on the experiment, it is concluded that MKB Enterprises should use the temperature $\left(235^{\circ} \mathrm{C}\right)$, pressure $(0.40 \mathrm{MPa})$ and cooling temperature $\left(5^{\circ} \mathrm{C}\right)$ to decrease the deviation from the mean value of weight of the pipes for 3-feet size. Pressure of $(0.42 \mathrm{MPa})$, temperature $\left(235^{\circ} \mathrm{C}\right)$ and cooling temperature $\left(5^{\circ} \mathrm{C}\right)$ for 4 -feet size should be used to achieve the desirable result for the response variable. Also it was concluded to implement the best solution and make sure it perform according to expectations. If there are deviation between what is expected and what is observed, determine the cause and take corrective actions. Also, develop controls using automatic controls or control charts and continue to observe the process to make sure that it remains productive.

\section{REFERENCES}

[1] W. Skinner, Manufacturing-Missing Link in Corporate strategy, Harvard Business Review 47 (1969) 136-145

[2] S.C. Wheelwright, Manufacturing strategy: Defining the missing link, Strategic Management Journal 5 (1994) 77-91

[3] R.H Hayes, S.C. Wheelwright, restoring our competitive edge: Competing through manufacturing, Wiley, New York, 1998

[4] C. Tunalv, Manufacturing strategy plans and business performance: A Framework and a Business analysis international journal of operation and production Management 12 (3) (1997) 4-24

[5] M. A Nobel, Manufacturing Competitive priorities and Productivity: An Empirical study, international journal of operation and production Management 12 (3) (1997) 85-99.

[6] G. Taninecz, Best Practices and performance, Industry week 246 (22) (1997a) 28-43.

[7] Hwang SK, Jang DH, Ko BD, Hwang BB. The forming characteristics of simultaneous radial-forward extrusion processes. Mater Sci Forum 2005;475-479:4171-4

[8] Cho HY, Min GS, Jo CY, Kim MH. Process design of the cold forging of abillet by forward and backward extrusion. J Mater Process Technol 2003;135:375-81.

[9] Lehmann, Erich L., and Joseph P. Romano. Testing statistical hypotheses. Springer Science \& Business Media, 2006.

[10] Dong, Jia, et al. "Evaluation and optimization of hepatocyte culture media factors by design of experiments (DoE) methodology." Cytotechnology 57.3 (2008): 251-261.

[11] Larson, David P., Leslie V. Powers, and Robert A. Hocker. "Cause effect diagram program." U.S. Patent No. 6,369,836. 9 Apr. 2002.

[12] Y. Kim, J. Lee, Manufacturing strategy and production systems: An integrated framework, Journal of Operations Management 11 (1) (1993) 3$\} 15$.

[13] R.H Chenhall, S.K Snell, The relationship between Strategic Priorities, Management techniques and Management Accounting: An Empirical Investigation using a systems approach, Accounting, Organization and Society 23(3) (1998) 243-264

[14] Brundtland, G., 1987. World Commission on Environment and Development, Our Common Future. Oxford University Press, Oxford, UK.

[15] Ford Motor Company, 2007. Sustainability Report 2007/08-Dagenham Engine Plant Case Study, /www.ford.com/microsites/sustainability-report-2007-08/ environment-case-dagenhamS, (accessed 31st July 2010).

[16] Fisher, Ronald Aylmer. "Design of experiments." Br Med J 1.3923 (1936): 554-554.

[17] Montgomery, D.C.Design and Analysis of Experiments, 3rd Ed.; Wiley: New York, 1991.

[18] Montgomery, D.C., Design and Analysis of Experiments. 2005: John Wiley \& Sons, Inc

[19] Shainin, D. and Shainin, P. (1988), "Better than Taguchi orthogonal tables", Quality \& Reliability Engineering International, Vol. 4, pp. 143-9

[20] Bhote, K.R. (1991), World Class Quality, American Management Association, New York, NY 